\title{
An area-efficient and high speed multiplexer for battery monitor system
}

\author{
Qidong Zhanga), Yintang Yang, and Changchun Chai \\ Institute of Micro-electronics, University of Xidian, \\ No. 2 South Taibai Road, Xi'an, Shaanxi 710071 \\ a)johnson0902.zhang@aliyun.com
}

\begin{abstract}
This paper presents a new area-efficient and fast sampling multiplexer for battery monitor system. This multiplexer structure introduces a full differential leapfrog sampling scheme which leads to half of occupied area, less sampling time and higher common mode rejection rate (CMRR) than the traditional one. This kind of multiplexer structure was introduced in a 12-ch battery monitor IC which fabricated with $60 \mathrm{~V}$ BCD process. The measurement result shows that the presented multiplexer achieves a channel mismatch error up to $1.2 \mathrm{mV}$ (Typical) while the battery monitor IC works in 400 ns sampling time.
\end{abstract}

Keywords: BMS, multiplexer, ADC, high voltage

Classification: Integrated circuits

\section{References}

[1] N. Noda: IEEE Int. Solid-State Circuits Conf. (ISSCC) (2010).

[2] R. K. Williams, L. T. Sevilla, E. Ruetz and J. D. Plummer: IEEE Trans. Electron Devices 33 (1986) 1977. DOI:10.1109/T-ED.1986.22856

[3] K. Hara, J. Sakano, M. Mori, S. Tamano, R. Sinomura and K. Yamazaki: Proc. Int. Symp. Power Semicond. Devices ICs (2005) 359. DOI:10.1109/ISPSD. 2005.1488025

[4] D. Aksin, M. AI-Shyoukh and F. Maloberti: IEEE J. Solid-State Circuits 41 (2006) 1938. DOI:10.1109/JSSC.2006.875305

[5] D. Aksin and I. Ozkaya: ESSCIRC, 2009. ESSCIRC '09 (2009) 136. DOI: 10.1109/ESSCIRC.2009.5326015

[6] J. Borg and J. Johansson: IEEE J. Solid-State Circuits 46 (2011) 475. DOI: 10.1109/JSSC.2010.2096113

[7] C. Birk and G. Mora-Puchalt: ISSCC Dig. Tech. Papers (2012) 376.

[8] S. J. Jung, S. K. Hong and O. K. Kwon: Electron. Lett. 50 (2014) 1900. DOI:10.1049/el.2014.1906

[9] K. Kadirvel and J. Carpenter: IEEE J. Solid-State Circuits 49 (2014) 928. DOI:10.1109/JSSC.2014.2300861

[10] C. L. Chen, D. S. Wang, J. J. Li and C. C. Wang: IEEE Trans. Very Large Scale Integr. (VLSI) Syst. 23 (2015) 244. DOI:10.1109/TVLSI.2014.2303989 


\section{Introduction}

Stacked high voltage battery monitor system is used for intelligent monitoring, charging and protection of Li-ion rechargeable batteries electric vehicles (EV) to ensure efficiency and safety [1], where many battery modules are integrated and assembled, which is shown in Fig. 1. A high supply voltage generated by these modules which are composed of many series of batteries. Battery monitor IC (BMI) is used to sense the battery information, e.g., voltage, temperature, current, etc. High voltage (HV) battery stacks need more BMI which will increase the system price and system reliability. To overcome this problem, more channels in one BMI are popular in industry. As the stacked battery channels increase, higher voltage devices are utilized to design the switches, however, it occupies more area than low voltage (LV) device does, besides, bigger parasitic parameters reduce the speed. Many papers focus on low area switches $[2,3,4,5,6,7,8]$, but they just focus on the area and speed of switches, and taking limited improvement. To save the whole chip area and speed, we propose a novel full differential leapfrog sampling.

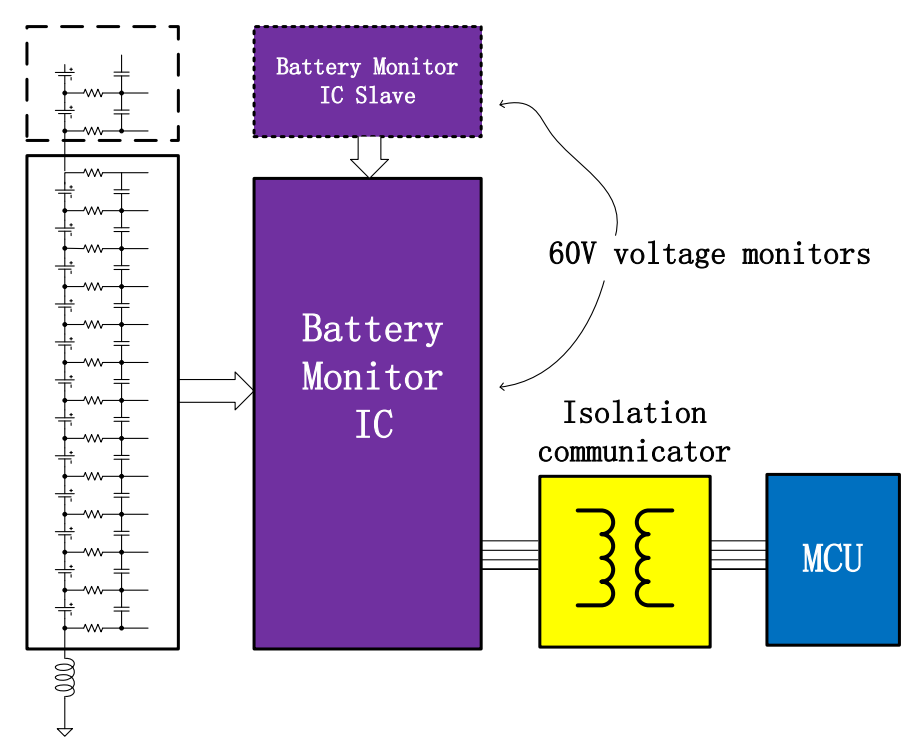

Fig. 1. A typical distributed stacked battery monitoring system.

\section{Circuit implementation}

Since HV devices occupy more area than LV devices, and the high voltage switch is one of the largest pieces in the chip. The measurement system introduces a leapfrog switch scheme and full differential structure, which just needs 13 high voltage switch (more than 24 for traditional) in 12 battery cells monitor system shown in Fig. 2, which consists of a 13:2 high voltage analog switchers $\left(\mathrm{SW}_{0^{-}}\right.$ $\mathrm{SW}_{12}$ ), high voltage dump switcher (S2), high voltage metal-oxide-metal (MOM) capacitor $\left(\mathrm{C}_{\mathrm{S} 1}-\mathrm{C}_{\mathrm{S} 4}\right.$, DAC capacitors), low voltage switchers $\left(\mathrm{S}_{3}-\mathrm{S}_{11}\right)$, Comparator and DAC. The HV block ground $\left(\mathrm{V}_{\mathrm{SSH}}\right)$ and power supply $\left(\mathrm{V}_{\mathrm{DDH}}\right)$ are theoretically isolated with $\mathrm{LV}$ blocks ground $\left(\mathrm{V}_{\mathrm{SSL}}\right)$ and power supply $\left(\mathrm{V}_{\mathrm{DDL}}\right)$. 


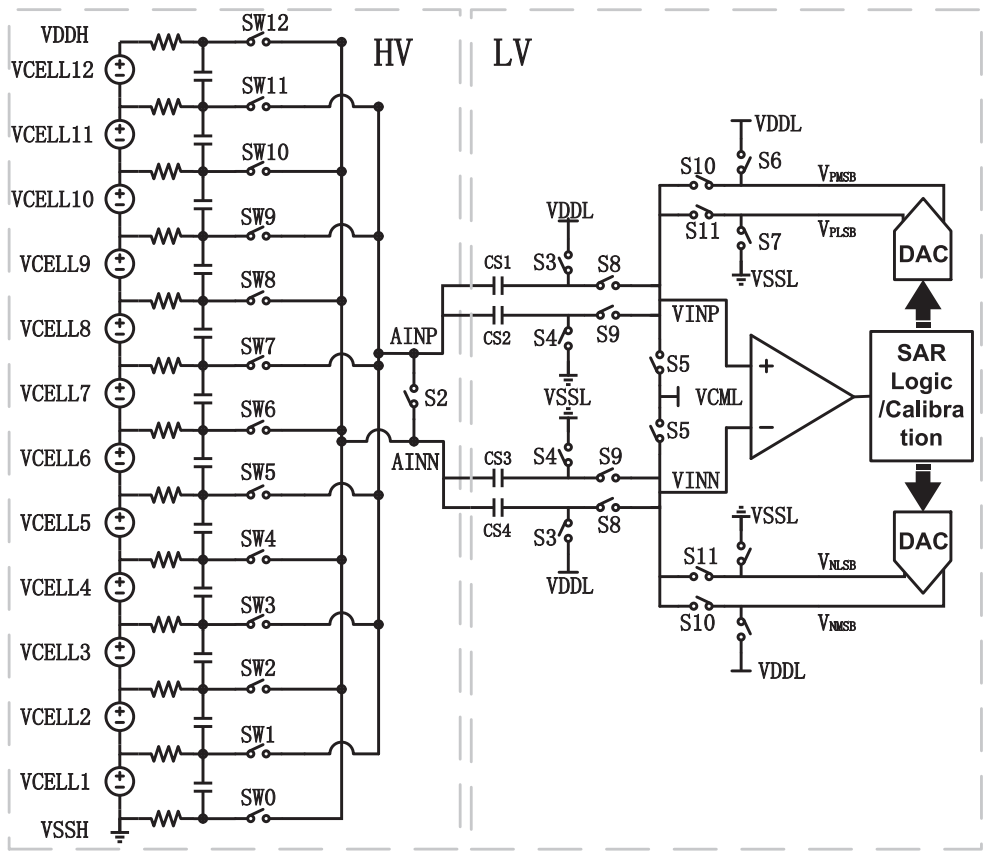

Fig. 2. The proposed high voltage multiplexer

A fully symmetry 12 bit DAC capacitors structure details is shown in Fig. 3.

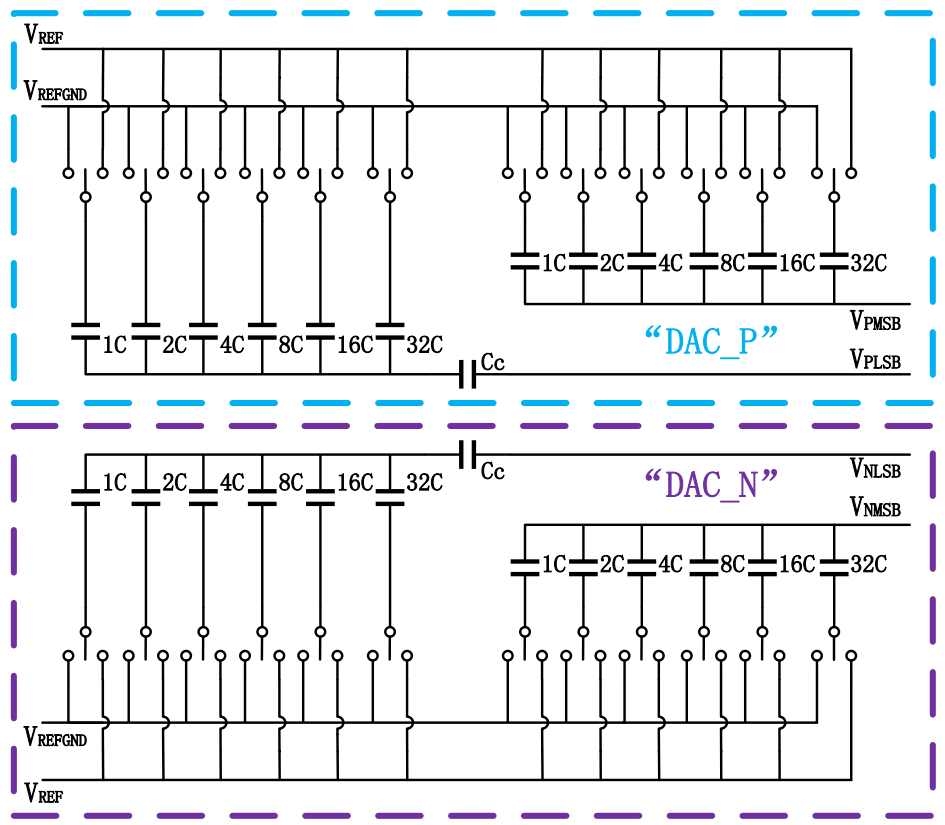

Fig. 3. The detail of DAC capacitors

Fig. 4 shows the switch working waveform. The switcher open schedule is $\mathrm{SW}_{2 \mathrm{n}}-\mathrm{SW}_{2 \mathrm{n}-1}, \mathrm{SW}_{2 \mathrm{n}-1}-\mathrm{SW}_{2 \mathrm{n}-2} \ldots \mathrm{SW}_{2}-\mathrm{SW}_{1}, \mathrm{SW}_{1}-\mathrm{SW}_{0}$. When $\mathrm{SW}_{2 \mathrm{n}}-\mathrm{SW}_{2 \mathrm{n}-1}$ is closed, it work in "even" mode, the ADC post processing block will use true form to process it, When $\mathrm{SW}_{2 \mathrm{n}-1}-\mathrm{SW}_{2 \mathrm{n}-2}$ is closed, it work in "odd" mode, the ADC post processing block will use complement form to process it. Since the serial cell common mode voltage will be $60 \mathrm{~V}$, so MOM cap is used as sampling and conversion capacitors. In this paper we explain the working state using an "even" scheme and a two segmented capacitor DAC structure as an example. 


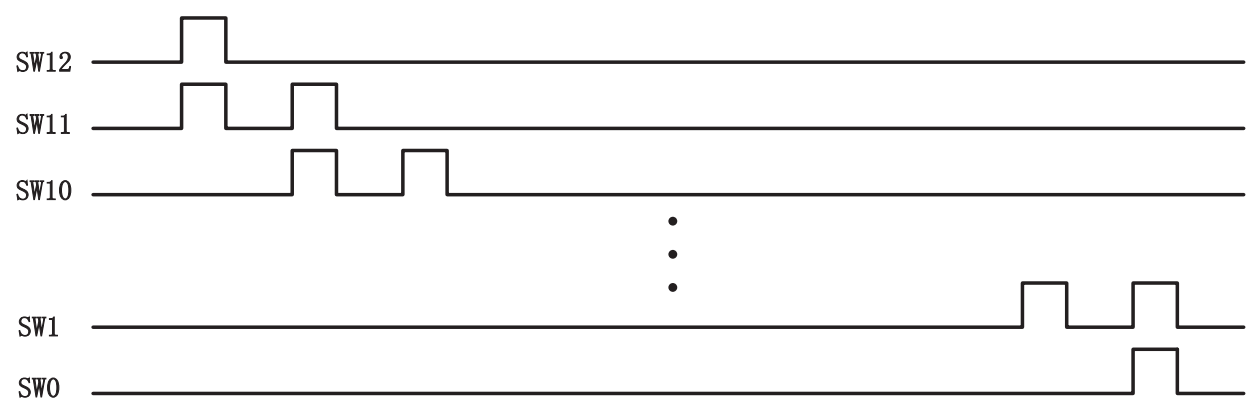

Fig. 4. The proposed high voltage switcher control signal

In sampling period, $\mathrm{SW}_{12}, \mathrm{SW}_{11}, \mathrm{~S}_{3}, \mathrm{~S}_{4}, \mathrm{~S}_{5}, \mathrm{~S}_{7}$, and $\mathrm{S}_{5}$ are closed, while other switchers are open. The cell voltage is stored in $\mathrm{C}_{\mathrm{S} 1}-\mathrm{C}_{\mathrm{S} 4}$ capacitors; the comparator common mode voltage is set to be $\mathrm{V}_{\mathrm{CML}}$; the DAC MSB and LSB capacitor will store different initial charge based on the initial DAC switcher state. In this state, the charge based on $\mathrm{V}_{\text {INP }}, \mathrm{V}_{\text {INN }}$ ports are

$$
\begin{aligned}
Q_{P 1}= & V_{D D L}\left(C_{S}+C_{M S B P}\right)+V_{S S L}\left(C_{S 2}+C_{L S B P}\right)-A_{I N P}\left(2 C_{S}\right) \\
& -V_{R E F}\left(C_{M S B P F}+C_{L S B P F}\right)-V_{R E F G N D}\left(C_{M S B P}+C_{L S B P}-C_{M S B P F}-C_{L S B P F}\right) \\
Q_{N 1}= & V_{D D L}\left(C_{S}+C_{M S B N}\right)+V_{S S L}\left(C_{S 4}+C_{L S B N}\right)-A_{I N N}\left(2 C_{S}\right) \\
& -V_{R E F}\left(C_{M S B N F}+C_{L S B N F}\right)-V_{R E F G N D}\left(C_{M S B N}+C_{L S B N}-C_{M S B N F}-C_{L S B N F}\right)
\end{aligned}
$$

Where $C_{M S B P}$ and $C_{\text {LSBP }}$ are total capacitor of high segment and low segment capacitor, $\mathrm{C}_{\mathrm{MSBPF}}$ and $\mathrm{C}_{\mathrm{LSBPF}}$ are capacitors connected to $\mathrm{V}_{\mathrm{REF}}$, all of them based on $\mathrm{V}_{\mathrm{INP}}$ port; $\mathrm{C}_{\mathrm{MSBN}}$ and $\mathrm{C}_{\mathrm{LSBN}}$ are total capacitor of high segment and low segment capacitor, $\mathrm{C}_{\mathrm{MSBNF}}$ and $\mathrm{C}_{\mathrm{LSBNF}}$ are capacitors connected to $\mathrm{V}_{\mathrm{REF}}$, all of them based on $\mathrm{V}_{\mathrm{INN}}$ port. $\mathrm{C}_{\mathrm{S} 1}-\mathrm{C}_{\mathrm{S} 2}$ are sampling capacitors, and assume $\mathrm{C}_{\mathrm{S} 1}=\mathrm{C}_{\mathrm{S} 2}=\mathrm{C}_{\mathrm{S} 3}=\mathrm{C}_{\mathrm{S} 4}$.

In converting period, $\mathrm{SW}_{2}, \mathrm{~S}_{8}, \mathrm{~S}_{9}, \mathrm{~S}_{10}$, and $\mathrm{S}_{11}$ are closed, other switchers are open, the charge of capacitor will distribute based on DAC cap switching. In this state, the charge based on $\mathrm{V}_{\mathrm{INP}}, \mathrm{V}_{\mathrm{INN}}$ ports are

$$
\begin{aligned}
Q_{P 2}= & V_{I N P}\left(2 C_{S}+C_{M S B P}+C_{L S B P}\right)-\frac{A_{I N P}+A_{I N N}}{2}\left(2 C_{S}\right) \\
& -V_{R E F}\left(C_{M S B P F}{ }^{\prime}+C_{L S B P F}{ }^{\prime}\right) \\
& -V_{R E F G N D}\left(C_{M S B P}+C_{L S B P}-C_{M S B P F^{\prime}}-C_{L S B P F}{ }^{\prime}\right) \\
Q_{N 2}= & V_{I N N}\left(2 C_{S}+C_{M S B N}+C_{L S B N}\right)-\frac{A_{I N P}+A_{I N N}}{2}\left(2 C_{S}\right) \\
& -V_{R E F}\left(C_{M S B N F}{ }^{\prime}+C_{L S B N F}{ }^{\prime}\right) \\
& -V_{R E F G N D}\left(C_{M S B N}+C_{L S B N}-C_{M S B N F}{ }^{\prime}-C_{L S B N F^{\prime}}\right)
\end{aligned}
$$

Where $\mathrm{C}_{\mathrm{MSBPF}}{ }^{\prime}$ and $\mathrm{C}_{\mathrm{LSBPF}}{ }^{\prime}$ are switching capacitors connected to $\mathrm{V}_{\mathrm{REF}}$ based on $\mathrm{V}_{\mathrm{INP}}$ port; $\mathrm{C}_{\mathrm{MSBNF}}{ }^{\prime}$ and $\mathrm{C}_{\mathrm{LSBNF}}{ }^{\prime}$ are switching capacitors connected to $\mathrm{V}_{\mathrm{REF}}$ based on $\mathrm{V}_{\mathrm{INN}}$ port. According to the Law of Conservation of Charge, $\mathrm{Q}_{\mathrm{P} 2}=\mathrm{Q}_{\mathrm{P} 1}$, $\mathrm{Q}_{\mathrm{N} 2}=\mathrm{Q}_{\mathrm{N} 1}$, the $\mathrm{V}_{\mathrm{INP}}$ and $\mathrm{V}_{\mathrm{INN}}$ voltages are derived as: 


$$
\begin{aligned}
& V_{I N P}= \frac{\left(\begin{array}{l}
\left(A_{I N N}-A_{I N P}\right) C_{S}+V_{D D L}\left(C_{S}+C_{M S B P}\right)+V_{S S L}\left(C_{S}+C_{L S B P}\right) \\
+\left(V_{R E F}-V_{R E F G N D}\right)\left(C_{M S B P F}{ }^{\prime}-C_{M S B P F}+C_{L S B P F}{ }^{\prime}-C_{L S B P F}\right)
\end{array}\right)}{\left(2 C_{S}+C_{M S B P}+C_{L S B P}\right)} \\
& V_{I N N}=\frac{\left(\begin{array}{l}
\left(A_{I N P}-A_{I N N}\right) C_{S}+V_{D D L}\left(C_{S}+C_{M S B N}\right)+V_{S S L}\left(C_{S}+C_{L S B N}\right) \\
+\left(V_{R E F}-V_{R E F G N D}\right)\left(C_{M S B N F}{ }^{\prime}-C_{M S B N F}+C_{L S B N F}{ }^{\prime}-C_{L S B N F}\right)
\end{array}\right)}{\left(2 C_{S}+C_{M S B N}+C_{L S B N}\right)}
\end{aligned}
$$

For $\mathrm{C}_{\mathrm{MSBP}}=\mathrm{C}_{\mathrm{MSBN}}=\mathrm{C}_{\mathrm{MSB}}, \mathrm{C}_{\mathrm{LSBP}}=\mathrm{C}_{\mathrm{LSBN}}=\mathrm{C}_{\mathrm{LSB}}, \mathrm{C}_{\mathrm{MSBPF}}=\mathrm{C}_{\mathrm{MSB}}-\mathrm{C}_{\mathrm{MSBNF}}$, $\mathrm{C}_{\mathrm{LSBPF}}=\mathrm{C}_{\mathrm{LSB}}-\mathrm{C}_{\mathrm{LSBNF}}, \mathrm{C}_{\mathrm{MSBPF}}{ }^{\prime}=\mathrm{C}_{\mathrm{MSB}}-\mathrm{C}_{\mathrm{MSBNF}^{\prime}}, \mathrm{C}_{\mathrm{LSBPF}}{ }^{\prime}=\mathrm{C}_{\mathrm{LSB}}-\mathrm{C}_{\mathrm{LSBNF}}{ }^{\prime}$

$$
V_{I N P}-V_{I N N}
$$

$$
=\frac{\left(2\left(A_{I N N}-A_{I N P}\right) C_{S}+2\left(V_{R E F}-V_{R E F G N D}\right)\left(C_{M S B P F}{ }^{\prime}-C_{M S B P F}+C_{L S B P F}{ }^{\prime}-C_{L S B P F}\right)\right)}{\left(2 C_{S}+C_{M S B P}+C_{L S B P}\right)}
$$

This structure shows excellent symmetric performance for differential input voltage and common mode input voltage, which is of great importance for "leapfrog switcher" structure.

\section{Experimental results}

The proposed design is implement using $0.18 \mu \mathrm{m} 60 \mathrm{~V}$ BCD process. Fig. 5a shows the chip micrograph which has high voltage multiplexer and ADC, and the chip occupy $4.1 \mathrm{~mm} \times 4.8 \mathrm{~mm}$ area. The details of high voltage switches were shown in Fig. 5b, and SW1 SW12 occupy $0.13 \mathrm{~mm} \times 0.5 \mathrm{~mm}$ area.

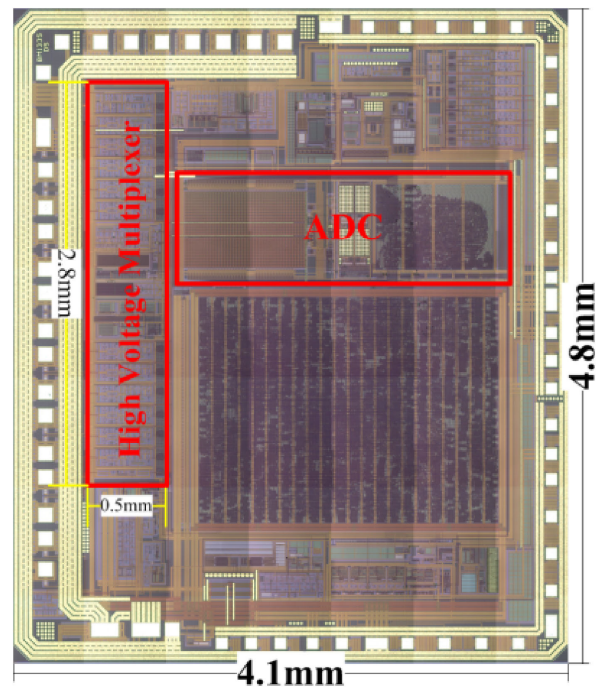

(a)

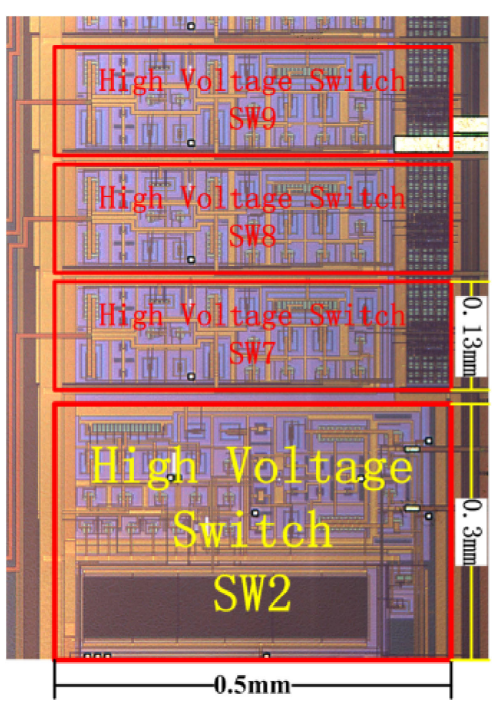

(b)

Fig. 5. Micrograph of fabricated multiplexer in BMI (a) and high voltage switcher details (b)

Fig. 6 shows the battery voltage errors with the high voltage multiplexer and 12 bit SAR ADC result with $-40^{\circ} \mathrm{C}$ and $125^{\circ} \mathrm{C}$. From the Fig. 6 the worst case measurement error of the 12 channels is $\pm 5 \mathrm{mV}$ when using $\pm 6.6 \mathrm{ppm}$ voltage reference. 


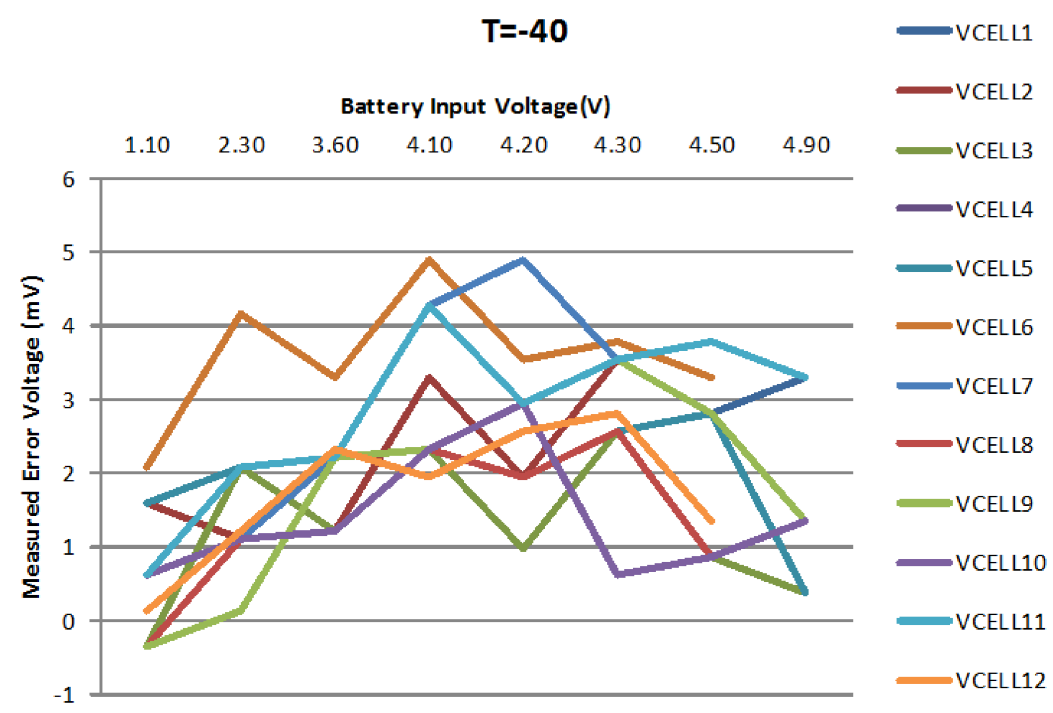

(a)

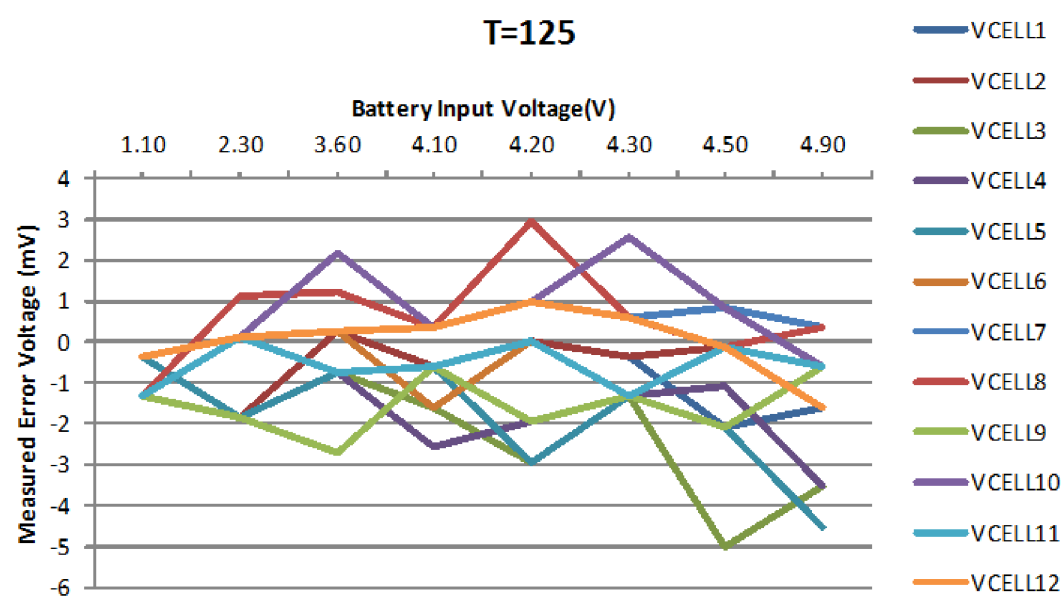

(b)

Fig. 6. (a) $\mathrm{T}=-40^{\circ} \mathrm{C}, \mathrm{ADC}$ Measured Error voltage for different input voltage for all 12 channels from $1-5 \mathrm{~V}$. (b) $\mathrm{T}=125^{\circ} \mathrm{C}$, ADC Measured Error voltage for different input voltage for all 12 channels from $1-5 \mathrm{~V}$. Data verified from $-40{ }^{\circ} \mathrm{C}$ to $125^{\circ} \mathrm{C}$ with internal reference.

Table I. Comparison of This Work with Published Literature

\begin{tabular}{|c|c|c|c|c|}
\hline Property & \multicolumn{2}{|c|}{ This Work } & [9] & {$[10]$} \\
\hline ADC Type & \multicolumn{2}{|c|}{ SAR } & $\Sigma \Delta$ & No ADC \\
\hline $\begin{array}{l}1 \text { channel ADC } \\
\text { Sampling Time }\end{array}$ & \multicolumn{2}{|c|}{1 us } & $>1 \mathrm{~ms}$ & N.A \\
\hline $\begin{array}{l}12 \text { channel ADC } \\
\text { Sampling Time }\end{array}$ & \multicolumn{2}{|c|}{12 us } & $>1 \mathrm{~ms}$ & N.A \\
\hline $\begin{array}{c}\text { Reference Voltage } \\
\text { Temperature } \\
\text { Coefficient }\end{array}$ & $\begin{array}{c} \pm 6.6 \mathrm{ppm} \\
\text { (a) } \mathrm{V}_{\mathrm{REF}}=2.5 \mathrm{~V}\end{array}$ & $\begin{array}{c} \pm 4.4 \mathrm{ppm} \\
\text { @ } \mathrm{V}_{\mathrm{REF}}=2.5 \mathrm{~V}\end{array}$ & N.A & N.A \\
\hline $\begin{array}{l}\text { Measurement } \\
\text { accuracy }\end{array}$ & $< \pm 5 \mathrm{mV}$ & $< \pm 3.5 \mathrm{mV}$ & $< \pm 5 \mathrm{mV}$ & $< \pm 12.7 \mathrm{mV}$ \\
\hline Area of $1 \mathrm{CH}$ & \multicolumn{2}{|c|}{$0.065 \mathrm{~mm}^{2}$} & N.A & $0.21 \mathrm{~mm}^{2}$ \\
\hline Temperature Range & $-40^{\circ} \mathrm{C} \sim 125^{\circ} \mathrm{C}$ & $-40^{\circ} \mathrm{C} \sim 105^{\circ} \mathrm{C}$ & $-40^{\circ} \mathrm{C} \sim 125^{\circ} \mathrm{C}$ & N.A \\
\hline
\end{tabular}


Table I provides a comparison of this work with similar IC from academia. The proposed multiplexer have 12 us sampling time for 12 stack connected batteries which faster than others. And the sampling switch area is $0.065 \mathrm{~mm}^{2}$ and the dumpling switch area is $0.15 \mathrm{~mm}^{2}$. The 12 channel HV switch total area is $1.4 \mathrm{~mm}^{2}$.

\section{Conclusion}

A $60 \mathrm{~V}$ high voltage area-effective multiplexer has been implemented in a $0.18 \mu \mathrm{m}$ CMOS technology with complementary high voltage DMOS devices. This high voltage multiplexer can be easily integrated in a possible SOC (system-on-chip) solution for high voltage BMS which occupy half of high voltage multiplexer area and faster sampling speed than traditional. The measurement result shows that our design is a high performance analogue high voltage multiplexer. And the channel mismatch error of the proposed HV multiplexer is smaller than $1.2 \mathrm{mV}$ (Typical) when $\mathrm{HV}$ multiplexer common voltage from $0 \mathrm{~V}$ to $60 \mathrm{~V}$ at the $400 \mathrm{~ns}$ sampling time. 